\title{
E-WOM ON THE ONLINE BOOKING INTERFACES - A COMPARATIVE ANALYSIS OF THE ONLINE TRAVEL AGENCIES' GUEST REVIEW SYSTEMS
}

\author{
Judit POÓRa , Gergely HORVÁTH \\ ${ }^{a}$ Hungarian University of Agriculture and Life Sciences, Georgikon Campus, associate professor, \\ Poor.Judit@uni-mate.hu \\ ${ }^{\mathrm{b}}$ PhD Student, University of Pécs, Faculty of Business and Economics gerisson21@gmail.com
}

Cite this article: Poór, J., Horváth, G. (2021). E-WOM on the online booking interfaces - a comparative analysis of the online travel agencies' guest review systems. Deturope. 13(1), 58-73.

\begin{abstract}
Recent profound and fundamental changes in information technology and electronics have led to a change in consumer habits, which also characterizes the tourism sector. In the e-world, consumers' information search and communication habits are changing; we are living in an era of a communicational paradigm shift. Online Travel Agencies (OTA) are not only the dominant channels of booking and sales nowadays, but also the channels of information gathering and guidance in the accommodation-related information of the services. Some of the information on OTA is objective; others are subjective - the latter being consumer information and opinions. Subjective information about the accommodation is provided by guest reviews on the OTA websites.

The present research aims at comparing the guest review systems of Hungarian and international OTA websites, in terms of authenticity, scale, the applied system of criteria, and the possibilities of guest evaluations broken down by target groups. In addition, this paper presents the OTA guest ratings of two accommodation establishments of the same category - located in the same destination - on a case-by-case basis, seeking an answer to the question of how consistent the results - as a whole and in terms of criteria - are for the consumer facing the decision.

In the further primary research part of the study, the review rating and customer feedback for satisfaction analysis is also presented based on professional interviews with hotel professionals.

The results reveal that the guest ratings, which provide the OTA users concise information about the accommodation establishment, are influenced by the scale and the categories (besides the calculation of the overall experience score) applied by the OTA, and the number of reviews, because a higher number of reviews gives a less scattered, more correlated with the other OTAs ratings.
\end{abstract}

Keywords: e-tourism, OTA, guest satisfaction, e-WOM, guest reviews

\section{INTRODUCTION}

Recent profound and fundamental changes in the field of information technology and electronics have led to a shift in consumer habits, which also characterizes the tourism sector. We live our daily lives in a digital environment defined by widespread access to the Internet and the use of information and communication technology (ICT) tools. In this e-world, consumers' information search and communication habits are changing; we live in an era of a paradigm shift of communication. Markos-Kujbus (2016) emphasizes that consumers nowadays want to get as much and as a wide range of information as possible in the shortest 
possible time, and that the Internet facilitates access to data and information (Katawetawaraks \& Wang, 2011). Accelerated lifestyles and technologies are forcing service providers to move forward and be up to date, thereby shifting their sales activities to the online world (Csendes $\&$ Kis, 2017). Because online sales have rather limited opportunities for customers to obtain information about products and services before making a decision, online sellers typically provide more product information that customers can use to make more well-established consumer decisions.

Accommodations mainly provide a service that - if done well - becomes a positive experience for people over time. It is important for the accommodations that the guests leave the venue with a pleasant experience, thus making them interested in returning. This is only possible if the guests are satisfied with the hotels' services. For satisfaction to develop in the guest's mind, it is necessary to provide an appropriate product or service on the part of the accommodation providers (Kátay, 2015). The aim of the accommodation provider is to sell as many exciting services as possible to its guests. Regular satisfaction measurements are important for establishing this.

In the field of online accommodation services, not only accommodation providers are the interested party, but also other participants, online accommodation agents: online travel agencies (OTA, e.g.: Booking.com, Szallas.hu), coupon companies (e.g.: BónuszBrigád.hu), and other online channels (e.g.: destination websites) (Csendes \& Kis, 2017).

Katawetawaraks \& Wang (2011) mentions as the most useful feature of the Internet, that it supports not only the pre-purchase, but also the post-purchase phase of a product and a service. In connection with this, Markos-Kujbus (2016) emphasizes that companies in the eworld are less able to control information and thus the consumer, as a result of which the consumer has the opportunity to decide what source of information to choose, to base their decision on information either from the company or from other participants, other consumers.

Information from other consumers may be particularly important for services, as services are not tangible - which partly leads to them to be heterogeneous - due to which service provider performances may vary (Lőke, Kovács \& Bacsi, 2018). The change in the perception of service provider performance is also due to the fact that the quality of service is subjective (Lovelock et al., 2004). Every consumer has different needs, which further complicates the possibility of the measurability of services. According to Schulze,Sidali \& Spiller (2014), in order to reduce tourism information asymmetries, consumers rely on several sources of information, of which electronic expression of opinion (experience, thought) based on consumers' previous experiences, online word of mouth (e-WOM) is a unique - more 
accurate, up-to-date, high-quality - information the consumer is provided during the decisionmaking.

Markos-Kujbus (2016) emphasizes that e-WOM is partly a communication channel, as it facilitates the flow of communication between consumers, and partly it is also a communication tool. The company - using its ability to influence - can try to control and influence the information and the communication transmitted about them. The content of the positive opinions is less relevant; the "quantity" of that is important because of the more favorable ratio of positive and negative opinions. In contrast, negative opinions are much more significant (Markos-Kujbus 2016). If the consumer has a bad experience with the hotel's services, he will develop dissatisfaction (Kotler \& Keller, 2016). It can often be detected with what purpose the consumer forms an opinion about his or her experiences (East, Hammond \& Wright. 2007). A good example of this is when the consumer wants to reduce his/her frustration by a negative entry, or if the consumer wants to dissuade others from buying a product or service (Bronner \& De Hoog 2011, Yen \& Tang 2015). According to Gwinner, Bitner \& Brown (2005), in order to achieve satisfaction, often not only is it necessary to take into account the individual needs of the consumer when forming an offer but also to take into account the individual behavior of the consumer, which is called adaptation. This means that if the organization manages to "incorporate" the consumer's personality into the offers as much as possible, the guest may be more satisfied before the booking is made.

The aim of our research is to compare the guest review systems of domestic and international OTA sites, in terms of authenticity, scale, the applied criteria system, and the possibilities of guest evaluations broken down by target groups. In addition, we present the OTA guest evaluations of two accommodation establishments of the same category - located in the same destination - on a case-by-case basis, looking for the answer to the question of how uniform the results seem - altogether and aspect-wise - for the consumer before the decision.

In the further primary research part of the study, based on professional interviews with hotel professionals, the guest satisfaction approach of OTA and accommodation is also to be presented.

\section{Satisfaction measurement in tourism}

Satisfaction surveys are very important for companies - and thus for accommodation service companies - to determine what level of satisfaction describes them, as this can determine the business success of the service activity (Gajić et al., 2019; Karakasné-Morvay, 2014; Oliver, 1997). From these studies, important information - to corporate leaders - can be extracted about their products and services, in terms of current and the expected future success 
(Dobbins, Niedrich \& Sharma, 1999). In the case of hotels, the primary form of measuring is inquiry and observation, which stems from the uniqueness of services. Hotels primarily use inquiry (questionnaire-based) as a method to measure satisfaction, which has the advantage of providing immediate feedback from guests about the performance of the services during and after being used. Satisfaction questionnaires are usually placed in the guest rooms by the hotel staff, but it is also possible to hand it over to the guest in person at the reception, or ultimately to send one electronically to the guests' mailbox (Karakasné - Morvay, 2014). For this reason, hotel management must not only focus on the operation of an impeccable accommodation, but also on paying more and more attention to learning about the lifestyle of their guests (Lóránt, et al. 2020) and to the very strong consumer trend about the growing environmental awareness (Chaker \& Ásványi, 2020, Hajmásy, 2018)

A Dobbins Niedrich \& Sharma, (1999) illustrates the guest satisfaction monitoring model formulated in Figure 1. Regarding the measurement of satisfaction, the authors emphasize that in addition to measuring 'total' satisfaction, it is also necessary to measure the factors that influence it, as the total level of satisfaction is dependent on the levels of satisfaction associated with the components. Measuring component associated satisfaction helps to identify the reasons for not meeting the target satisfaction level.

Figure 1 Satisfaction monitoring model

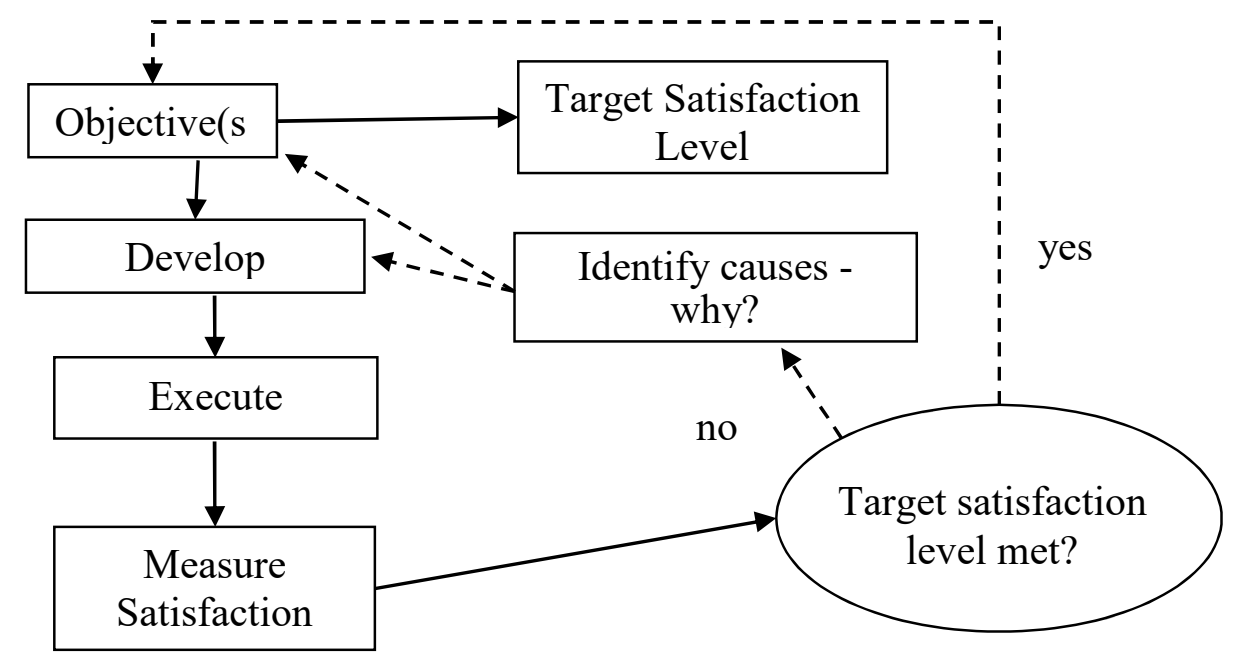

Source: Dobbins, Niedrich \& Sharma. (1999)

Many factors influence the satisfaction-aspect based opinion of a target area. These include the number of the accommodation's services, the uniqueness of the product or service, the price, the price/value ratio, and at the same time, the behavior, expertise, and personality of 
the people working in the accommodation also strongly influence this. The satisfaction models used in tourism summarize the following aspects:

1. Consumer experiences, which cover the quality of products or services,

2. Staff characteristics (e.g., preparedness, personality, etc.),

3. The quality of the services used,

4. Consumer experiences, developed after using the service,

5. The quality of relationships, formed between the service provider and the consumer. (Karakasné Morvay \& Daruka, 2009)

When making a travel decision, we first choose an area as the destination, then an accommodation. The consumer changes his/her place of residence during a trip in order to gain experience, so the aim of the organizations in the destination areas is to provide a system of conditions necessary for the consumer experience, so that the guest can feel at home in a "foreign place". The existence of the material conditions necessary for the development of the experience, as well as the existence of other services, are strong influencing factors in making a decision regarding accommodation. Nowadays, the expectations of the demand side "dictate", and these are mainly determined by quality. In the case of products and services, if the quality is unsatisfactory, then the consumer feels disappointed by the product, that he/she did not get what was to be expected and was deprived of the pleasurable experience. If the guests' feedback on the accommodation appears to require a change in the services, apart from the hotel location, this can be done at a lower cost (Kátay, 2015).

\section{RESEARCH ISSUES AND METHODOLOGY}

OTA systems are not only the channels of booking and sales but also the channels of information gathering and orientation related to accommodation services, some of which is objective, others subjective, the latter being consumer information and opinions. The subjective information about the accommodation is provided by the guest reviews on the OTA websites. The present research focuses on two areas: the main objective is to examine the correlation of the scale values found in different OTA guest review systems of the same accommodation, partly for the same aspects and partly for the overall satisfaction level, looking for the answer to the question of whether the decision-making consumer meets a different average satisfaction level, or a similar 'average' opinion, regardless of the OTA system. For a given hotel, a similarly interesting question may be, whether the guest evaluation results for homogeneous groups develop in the same way or not. To this first we compare the guest review systems of some domestic and international OTA sites, which are the following: Booking.com, HRS.com, Szallodak.hu, Szallas.hu, Szallasvadasz.hu, Belfoldipihenes.hu, Utazzitthon.hu. 
Second, we use professional interviews to examine to what extent the guest evaluation information displayed on the OTA websites provides a true picture of the accommodation, and to what extent hotel management utilizes the information provided there. Based on the above, answers were sought to the following research questions in the study:

Q1: On what criteria can consumers rely when they evaluate the accommodation through the OTA websites?

Q2: How consistent are the criteria on the different OTA websites? (How similar are the criteria on which different OTA websites base their evaluations?)

Q3: What is the hotel managers' opinion about the accommodation sales on OTA sites and about the results and consumer opinions that appear there? (Is what the guest writes/wrote about the venue authentic or not?)

The interviews were conducted with senior individuals (managers, managers, directors) who have previously and still do currently work in the hotel industry. Upon the interviews, snowball sampling was also included into the methodology which means that the interviewees were always asked for suggestions of additional interviewees after the interviews (Kolos \& Kövesdi, 2020). The professional interview was conducted with 17 people in 2019-2020. In this case it was important to find accommodations and managers for the interviews who are familiar with how the OTAs' systems operate from the accommodation's point of view.

\section{RESULTS}

\section{Guest reviews for online travel agencies}

In recent years, regarding hotel reservations online channels and transactions have become widespread. This change is partly due to the emergence of OTAs. Nowadays online travel agencies are not only the important channels of booking and sales, but also the channels of information gathering/acquisition and dissemination related to accommodation services, so they serve both as marketing and distribution channels.

Many valuable pieces of information can be found on OTAs websites, part of which is objective (e.g. price); others are subjective. The latter are the guest reviews, customer opinions, and evaluations. This subjective information about the travel experiences, or, e.g., accommodation can be text or score on OTA websites.

The purpose of this paper is to compare the guest review system of the most popular Hungarian and international OTA websites (as summarized in Table 1), the main aspects of which are: authenticity, scale, criteria system, and guest categories (groups/types). 
Among the guest review systems of the examined OTA websites, Booking.com, Szallasvadasz.hu and Szallas.hu ensure that the reviews are 100\% genuine, so decisionmakers gathering information on the website can only meet with verified reviews, authentic ratings and personal experience. The guest reviews on Szallasvadasz.hu have been written by guests who have already stayed at the accommodation. After the guest leaves the accommodation establishments, they receive an email with the questionnaire to fill out to express their subjective opinion. Booking.com has the most detailed public description about its own guest review system (from getting and managing to dealing with and responding to guest reviews), which not only ensure for the user, both the travelers and the accommodation owners, that the reviews are genuine, unique and up-to-date (no more than 36 months old), but helps the accommodation owners using the guest review system to imply greater satisfaction.

The questionnaire sent to the guest contains questions that allow customers to rate the overall experience or the attributes of the accommodation establishments and the services offered and questions that allow the guests to describe their travel experiences. As a result of a numeric/rating questionnaire, a score measured by values provide concise, therefore clearer and more efficient information about the accommodation establishments. As Filiery and McLeay (2015) highlight, the overall rating of accommodation summarizes the relative proportion of positive, negative, and neutral reviews. A better score reflects a better accommodation establishment. This information is useful for the consumers who may use these ratings for decision-making instead of reading the full content of online reviews. So naturally, a higher overall rating contributes to increasing online sales (Martin-Fuentes et al., 2020).

OTAs examined by us use different guest review systems but with a Likert scale for collecting ratings; 3-3 of them use a 1-5 and a 1-10 rating scale, and only the Szallodak.hu uses a 1-11 rating scale. Regarding the methodology, opinions are divided on the number of scale points and the use of even or odd response options (Zerényi, 2016). In the case of an even number of rating scale there is no possibility to express a neutral relationship. Besides, in case of more than a five-point scale, the denomination of the points is difficult.

Besides the overall experience, guests can rate the accommodation establishment in some specific areas. Just like the OTAs differ in the number of scale points, they differ in the number and the content of these categories. Regarding the aspects, a kind of uniformity can be formulated with regard to the content of 5-6 aspects, in which HRS and Belfoldipihenes.hu differ. The former is due to the detail of the criteria system. The OTA guest review systems uniformly provide the staff evaluation. Except for Booking.com, the restaurant's rating, except Belfoldipihenes. $h u$ the measurement of satisfaction with the cleanliness and the value for 
money/price-quality ratio is displayed in the OTAs' system. In connection with this, we would note that sometimes, the same content can be identified for the different categories of OTAs (e.g. accessibility/location). The location and the comfort are not rated by HRS and the Belfoldipihenes. $h u$ guest review system, or in the case of the former comfort is rated only in connection with the bed. Nevertheless, in case of Szallasvadasz.hu the comfort of the room is rated. It should be noted that there are two categories (facilities and free wifi) rated only by the international OTA websites. The former is rated on Booking.com and HRS.com, while the latter category is only found on Booking.com. The categories of the OTA guest review systems are compared in Table 1. So while guests can rate five categories on Befoldipihenes.hu and six categories on Booking.com, they can rate twelve categories on HRS.com.

Table 1 Categories of Online Travel Agencies' reviews

Categories

OTA

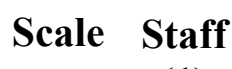

Clean- Value for

(1) liness money

(2)

(3)

Comfort Location Service Restaurant

$\begin{array}{cccc}\text { Booking.com } & 10 & + & + \\ \text { HRS.com } & 10 & + & + \\ \text { Szallodak. } h u & 11 & + & + \\ \text { Szallas.hu } & 10 & + & + \\ \text { Szallasvadasz.hu } & 5 & + & + \\ \text { Belfoldipihenes. } h u & 5 & + & \\ \text { Utazzitthon. } h u & 5 & + & +\end{array}$

Categories of HRS:

(4)

(5)

(6)

(7)

$\begin{array}{ll}+ & + \\ + & \\ + & + \\ + & + \\ + & + \\ + & +\end{array}$

$\begin{array}{ll}+ & + \\ + & + \\ + & + \\ + & + \\ + & +\end{array}$

$\begin{array}{lll}+ & & \\ + & + & + \\ + & + & + \\ + & + & + \\ + & + & +\end{array}$

Value for money (3)

Categories of Belfoldipihenes.hu:

Ambience/atmosphere in hotel

Friendliness of staff (1)

Hotel

Staff (1)

Willingness to assist (1)

Wellness

The quality of breakfast (7)

Restaurant (7)

Restaurant quality (7)

Spa facilities

Room size

Room facilities

How comfortable the beds are

( 4)

Bathroom

Room

+
+
+
+
+
+

Cleanliness of hotel (2)

Sourc

edition on the basis of OTA websites

e:

own 
Usually, the final score of the accommodation establishments is the arithmetic mean of the ratings of the categories. The guest review system of Booking.com is more complex and special from the point of view that guests rate the categories by only four Likert points (2.5-10 rating scale) using smile faces (poor-fair-good-excellent), and they rate their overall experience with a 1-10 rating scale. So the overall score is not the arithmetic mean of the scores for the categories. Because the final score is not average, the only question the guests are required to answer to submit their review is about the overall experience (Booking.com, 2020).

Related to Figure 2, Martin-Fuentes et al. (2020) highlight that the denomination of the scale points on some OTAs is more positive than negative partly because of the even number of scale points. In case of Booking.com, the second point is denoted as the neutral point with the neutral smiley.

Figure 2 Guest review form for Booking.com

\section{Rate this property:}

\begin{tabular}{|c|c|c|c|c|c|c|c|c|c|}
\hline \multicolumn{7}{|c|}{ How was your stay? } & \multirow{2}{*}{$\begin{array}{c}\begin{array}{c}\text { (-) } 8 \\
\text { Very good }\end{array} \\
8\end{array}$} & & \\
\hline 1 & 2 & 3 & 4 & 5 & 6 & 7 & & 9 & 10 \\
\hline
\end{tabular}

Staff

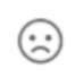

Facilities

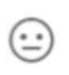



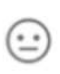

$\odot$

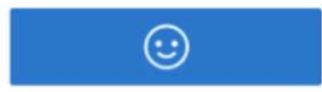

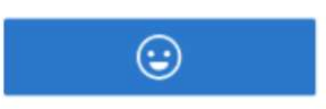

\section{(-)}

$\odot$

Source: Booking.com Partner Hub (2020)

\section{Online guest reviews of OTAs in practice - case study (q1-q2)}

In the following, we present the online guest reviews of two (while maintaining the anonymity, 'A' and 'B') four-star hotels in the same destination. The distribution of guest reviews among OTA systems is very different, despite the fact that the two hotels of the same category are located in the same area: in one case, a high proportion of guest reviews is concentrated on an international OTA system and for the other on the domestic, Hungarian 
OTA systems (Table 2). One of the two hotels is not present on HRS and Szallodak.hu, and the second on Szallodak.hu and Belfoldipihenes.hu.

When comparing the overall scores of the two hotels, it can be concluded that Hotel ' $\mathrm{B}$ ' received a better rating in all of the examined OTA guest review systems. A final score, independent from OTAs, can be calculated based on OTAs' overall score; it is an average weighted by the number of guest reviews. Since the number of guest reviews is unknown (not available) for Belfoldipihenes.hu, we could not consider this OTA's rating.

Table 2 OTAs' reviews for two hotels

\begin{tabular}{|c|c|c|c|c|c|c|c|c|}
\hline \multirow[t]{2}{*}{ OTA } & \multicolumn{2}{|c|}{$\begin{array}{c}\text { Number of guest } \\
\text { reviews }\end{array}$} & \multirow[t]{2}{*}{ Scale } & \multirow{2}{*}{$\begin{array}{l}\text { Number of } \\
\text { categories }\end{array}$} & \multicolumn{2}{|c|}{ Final score } & \multicolumn{2}{|c|}{$\begin{array}{l}\text { Final score } \\
\text { (re-scaled) }\end{array}$} \\
\hline & $\mathrm{A}$ & $\mathrm{B}$ & & & A & $\mathrm{B}$ & A & $\mathrm{B}$ \\
\hline Booking.com & 101 & 1000 & $1-10$ & 7 & 7.70 & 8.60 & 3.98 & 4.38 \\
\hline HRS.com & - & 5 & $1-10$ & 12 & - & 8.80 & - & 4.47 \\
\hline Szallas.hu & 1187 & 329 & $1-10$ & 7 & 8.70 & 9.10 & 4.42 & 4.60 \\
\hline Szallasvadasz.hu & 839 & 117 & $1-5$ & 7 & 4.21 & 4.66 & 4.21 & 4.66 \\
\hline Belfoldipihenes.hu & $?$ & - & $1-5$ & 5 & 4.60 & - & 4.60 & - \\
\hline Utazzitthon.hu & 95 & 13 & $1-5$ & 7 & 4.10 & 4.50 & 4.10 & 4.50 \\
\hline $\begin{array}{l}\text { Total } \\
(\mathrm{CV}, \%)\end{array}$ & 2222 & 1464 & $1-5$ & - & - & - & $\begin{array}{l}4.31 \\
(3.0)\end{array}$ & $\begin{array}{l}4.46 \\
(2.6)\end{array}$ \\
\hline
\end{tabular}

Source: own edition on the basis of OTA websites

To compare ratings with the same scale and calculate the mean, independent from the OTAs, we first used linear transformation to re-scale the scores to $1-5$ in case of 1-10 or 1-11 rating scale systems. Several methods can be found in the literature. Martin-Fuentes et al. (2020) rescaled the scores of each OTA to 0-10 rating scale with the min-max normalization method. Dawes (2012) presents a simple arithmetic procedure whereby the scale endpoints for the 1-5 and 1-7 rating scales are anchored to the endpoints of the 1-10 rating scale, and the intervening scale values are inserted at equal numerical intervals. But this method is difficult to apply for a 1-11 rating scale or re-scaling non-integer score values.

The dispersion of the OTAs' final guest ratings was also examined by the coefficient of variation $(\mathrm{CV})$, the value of which is around $3 \%$, i.e., the difference between the guest evaluation results of the OTA pages is negligible.

For the two hotels, we compare the scores of 4 OTA systems for five identical aspects beyond the overall experience. We compare the scores of 3 OTA systems for seven identical aspects beyond the overall experience (see Figure 3). 
Figure 3 OTAs' reviews for the categories of two hotels

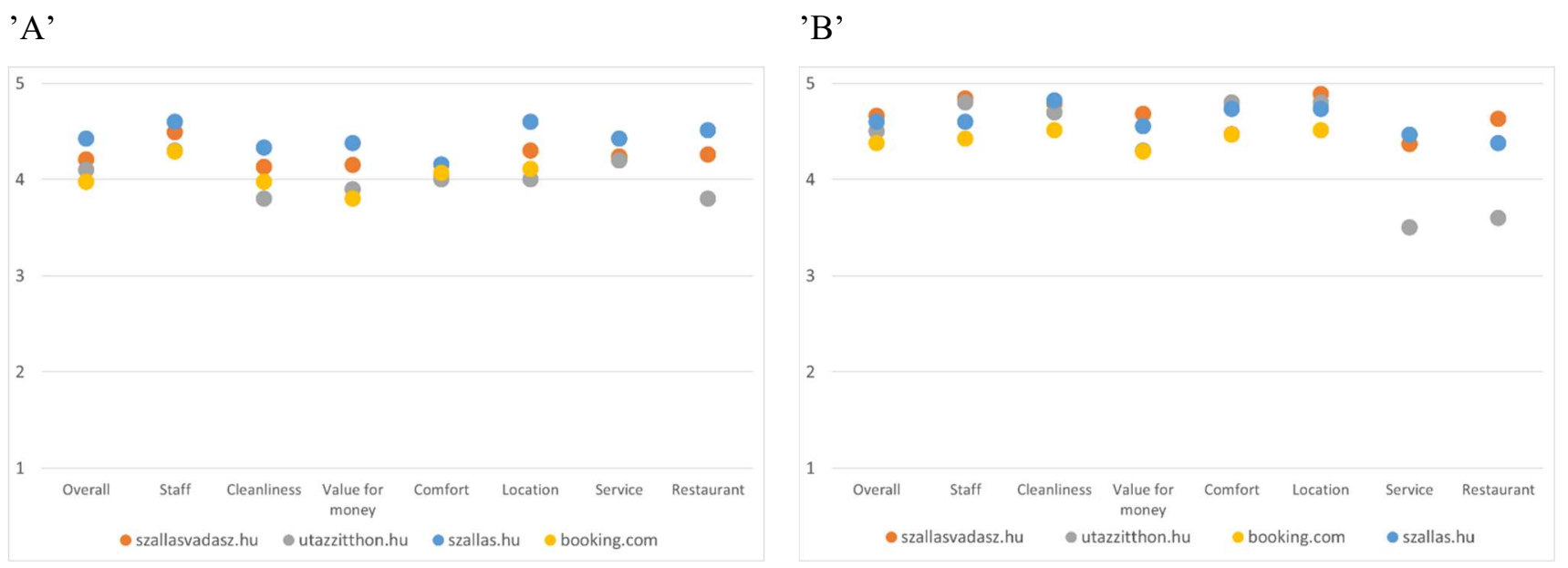

Source: own edition on the basis of OTA websites

Using the re-scaling to a five-point scale - we examined the extent to which the scores of OTA systems according to the different aspects correlated with each other. For the correlation analysis, we used the Spearman's rank correlation coefficient, which takes a value between -1 and +1 , indicating the direction and strength of the relationship.

In the case of Hotel 'A', the strongest correlation was found between the score of Szallas.hu and Szallasvadasz.hu (0.986 - and as it can be seen in Figure 3 and in Figure 4, the guests of Szallasvadasz.hu evaluate a little bit more critically), between the Szallasvadasz.hu and the Utazzitthon.hu the value of the coefficient was 0.667, while between the Booking.com and the Utazzitthon. $h u$ the indicator gave a value of 0.647 , in other cases we calculated a value between 0.5 and 0.6. Omitting the Booking.com, we could compare the scores from 8 same points of view. In this case, the value of the indicator increased even more in the comparison between Szallas.hu and Szallasvadasz.hu (0.988), but the degree of their correlation with the Utazzitthon.hu decreased $(0.384 ; 0.434)$.

Correlation analysis for Hotel ' $\mathrm{B}$ ' shows different results. For the 8 points of view the correlation coefficient of Szallas.hu and the Utazzitthon.hu showed a stronger correlation (0.778). However, in the case of the Utazzitthon.hu, the scores for categories are probably more scattered due to the lower number of guest reviews. Contrary to the above results for Hotel 'A', the ratings of Szallas.hu and Szallasvadasz.hu indicated the lowest relationship (0.494). Including Booking.com in the analysis, we already experienced the strongest correlation between Szallas.hu and Booking.com (0.940 - less number of items), Booking.com with the Utazzitthon.hu gave the same value of 0.647 as in the case of the other hotel. In other cases, the value of the indicator became 0.50 or less. 
Figure 4 The ratings of the most correlated OTAs guest reviews for the different categories

'A'

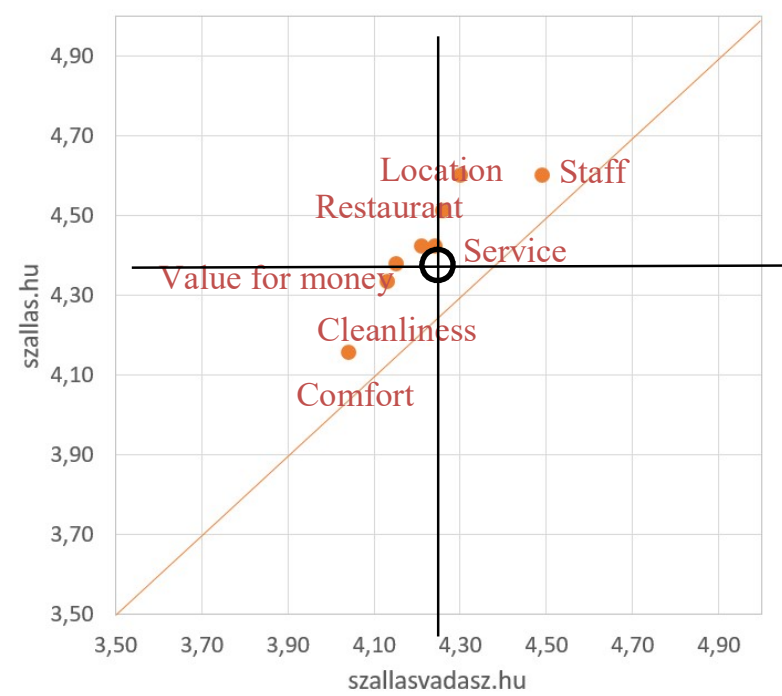

'B'

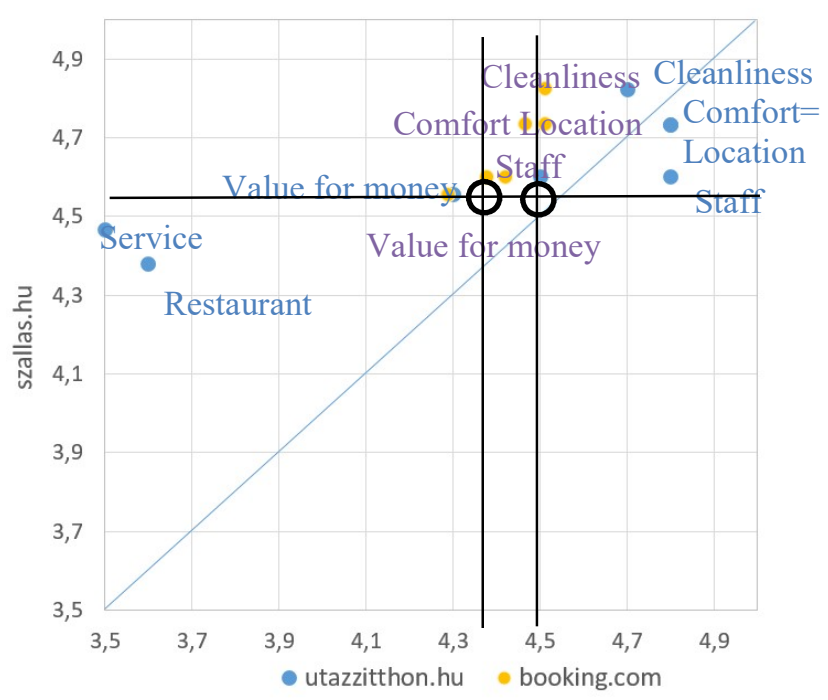

Source: own edition on the basis of OTA websites

How can we evaluate the results, what conclusions can be drawn?

Our results show that the correlation was the strongest among those OTAs with the highest number of guest reviews. The results of systems with higher guest reviews are less sensitive to individual evaluations, then. Thus "on average" reflect similar evaluations and consequently stronger relationship. Satisfaction with each aspect counts almost equally in overall satisfaction and is evaluated in a similar way to overall satisfaction.

As it can be seen in Figure 4, the scores on Szallas.hu are usually higher, not only in case of overall experience, but also in case of different areas. Martin-Fuentes et al. (2020) compared five OTAs (Agoda, Attrapalo, Booking, HRS and Travel Republic) hotel ratings and they found that after re-scaling the scores the worst ratings were found on Booking.com. On the basis of our result the similar outcome can be stated, that is, for the examined two hotels the re-scaled scores of Booking.com are usually the lowest compared to the other OTAs.

As it can be seen in Figure 4, it depends on the accommodation establishment which categories are overrated or underrated compared to the overall experience. While in the case of Hotel ' $A$ ' the guests were relatively satisfied with the restaurant or service, in the case of Hotel ' $\mathrm{B}$ ' they were relatively dissatisfied with them. We can state it even though the results of the Booking.com cannot prove this, because of the lack of these categories in their evaluation. But we can see on the basis of the results that most of the existing categories are overrated compared to the overall experience, so the guests are less satisfied with something 
else. The textual reviews are important in such cases to identify the poor areas, or the ratings of the other OTAs can help the tourism managers too.

\section{Results of professional interviews (Q3)}

Many hotels sell on online booking interfaces. This is partly due to the fact that these OTA websites are known to much more people than the selected locations and the accommodations. Suppose the consumers facing the choice have an idea of the place to travel but do not know what optional accommodations are available. In that case, they may not know the exact name of the accommodation for the booking. However, after selecting a location on the OTA websites, it is possible to learn about the providers offering accommodations.

During the primary research, the interviewed tourism professionals stated that they consider the guest entries on the OTA websites authentic. In many cases, managers are aware if something is wrong with the accommodation; the feedback - including the access and scores on the OTA websites - can also help with confirming this.

The consumer often does not personally indicate his or her problem or complaint of the accommodation on the spot. This will result in a bad opinion when leaving the accommodation. However, if the problem is communicated, the service providers will try to solve it. According to the interviewees, the best way to deal with complaints is to find out what reasons lie behind the differences between consumer expectations and the provision of such services, to which consumers can also draw the management's attention. In the event of a complaint, it can mean a lot if the accommodation apologizes to the consumers. They might not be completely satisfied, but at least they will not leave the accommodation with a "bad taste left in their mouths". Examining the contexts of the OTA, it can be concluded that if there is a complaint occurring at the accommodation, the way it is handled can affect the consumer's satisfaction, and thus the evaluation scores he/she gives to the OTA site. Consequently, it also affects the role of e-WOM.

Interviewees agree that there is no good way to avoid negative word of mouth. It is a mitigating factor if the accommodation apologizes to the consumers in relation to their complaints, which may reduce the spread of negative word of mouth. Positive word of mouth, on the other hand, is beneficial to the hotel. In marketing, it is important that all information be credible, as it also influences the consumer's opinion about the accommodation. 


\section{CONCLUSIONS}

Today, we live in an "era" of the Digital Age, so accommodation companies essentially must direct their sales activities towards the online world as well. Consumers nowadays are also looking more and more for prior information about accommodations in the online world. Online travel agencies (OTA) are not only the dominant channels of booking and sales anymore, but also the channels of information gathering and the guides of accommodation services related information. Thus, we can say that the "set" of information about different accommodations on the so-called OTA site helps many consumers gather preliminary information about accommodations. In connection with this, in the present research, the guest evaluation systems of Hungarian and international OTA sites were compared based on different aspects (e.g., authenticity, scale, etc.). Furthermore, OTA guest ratings were presented from two accommodations of the same category, looking for the answer to the question of how coherent the results are as a whole and by criteria presented to the consumerfacing the decision.

The results show that the OTA use of accommodation establishments - of the same category and close geographical location - can be very different, which is also visible from the number of guest evaluations of the respective OTA systems and their distribution.

The answer to our first and second research question (Q1- Q2) is that each OTA guest rating system operates on a different scale and criteria system, making it difficult for the users to compare the ratings. Not only the number but also the content of the categories is different; nevertheless, a kind of uniformity can be formulated with regard to the content of 5-6 aspects, which allows for comparison of 3-4 OTA guest review system (of the OTAs, examined by us). The different scale and criteria system influences the differences in the individual OTA guest evaluation results, but - based on the above mentioned two examples - is probably not decisive in the overall evaluation.

\section{SUMMARY}

Regardless of the OTA site, behind the overall result, an individual evaluation and thus a guest stands, with his/her own subjective perception and experience. Guests rate the same property differently, and in the case of lower numbers of guest ratings, the overall rating results are more sensitive to individual ratings. However, the results of our own study showed that those OTA guest ratings performed the most similarly that had the highest number of guests leaving reviews. Meaning, the results of systems providing higher guest ratings are less sensitive to individual evaluations and thus "typically" reflect similar evaluations that show changes that are closer to each other; in the overall satisfaction, the satisfaction with the certain aspects weighs nearly equal, and it is also similarly valued.

For both the hotel and the consumer, who is about to make a decision, "average" evaluations that are not distorted by extreme individual opinions are important, identifying weaker and stronger factors of the performance along with the criteria system, but at the same time, besides the point-based reviews, 
individually written evaluations on OTA websites are equally important, which were not addressed at the level of analysis in the present study. Meanwhile, interviews revealed the importance of how these feedbacks from guests. The answer to our third research question (Q3) about the hotel managers' opinion is that they consider the guest entries appearing on the OTA websites to be authentic. The feedback including the entries and scores on the OTA websites - can help them to identify the problems. The response to guest reviews, and the handling of problems will play a key role in future word-of-mouth advertising related to the accommodation, and even e-WOM.

Our research assumes that the different scales of OTAs influence the ratings of the same accommodation establishment. That is a fact since the number of scale points influences the evaluation; e.g. it can be odd or even. Therefore, we can express the neutral review or not. In conclusion, the diversity of OTAs scale and criteria system has a negative effect on the OTA users (travelers and accommodation providers) because of the difficulty of comparison. The systems should be harmonized. However, we cannot determine the extent of the influencing effect of differences in systems, because many other factors influence the ratings, e.g., the users of the OTAs. The future goal can be to further examine the individual ratings on the OTA websites to find out how these entries shape the overall OTA ratings.

\section{Acknowledgement}

We acknowledge the financial support of Széchenyi 2020 under the EFOP 3.6.1-16-2016-00015 project

\section{REFERENCES}

Booking.com Partner Hub (2020). How is my Guest Review Score generated? Retrieved from: https://partner.Booking.com/en-us/help/guest-reviews/how-my-guest-reviewscore-generated. (date of download 12/12/2020)

Bronner, F., \& De Hoog, R. (2011). Vacationers and eWOM: Who Posts, and Why, Where, and What? Journal of Travel Research, 50(1), 15-26.

Chaker, H., \& Ásványi, K. (2020). CSR values and activities of Green Hotels in Hungary. In: Marton, Zs.; Németh, K.; Pelesz, P.; \& Péter, E. (eds.) IV. International Scientific Conference on Tourism And Security (pp. 428-438). Nagykanizsa, Hungary: University of Pannonia, Nagykanizsa Campus.

Csendes, I., \& Kis, G. (2017). Online activity of accommodation providers in Hungary. In: Deutsch, N (eds.) Diversity of Business Development: Volume I. Directions, Trajectories and Strategies (pp. 135-146). Saarbrücken, Germany: Lambert Academic Publishing (LAP).

Dobbins, G., Niedrich, R. W., \& Sharma, S. (1999). A Framework for Monitoring Customer Satisfaction: An Empirical Illustration. Industrial. Marketing Management, 28(3) 231243

Dawes, J. (2008). Do data characteristics change according to the number of scale points used? An experiment using 5 point, 7 point and 10 point scales. International Journal of Market Research, DOI: 10.1177/147078530805000106

East, R., Hammond, K., \& Wright, M. (2007). The relative incidence of positive and negative word of mouth: A multicategory study. International Journal of Research in Marketing. 24(2). 175-184.

Filiery, R., \& Mcleay, F. (2015). E-WOM and Accommodation: An Analysis of the Factors That Influence Travelers' Adoption of Information from Online Reviews. Journal of Travel Research, 53(1) 44-57.

Gajić, T., Vujko, A., Tretiakova, T.N., Petrović, M.D., Radovanović, M., \& Vuković, D. (2019). Evaluation of Service Quality Based on Rural Households' Visitors - Serbian Case Study. Deturope, 11(2) 4-21.

Gwinner, K. P., Bitner, M. J., \& Brown, S. W. (2005). Through Employee Adaptiveness. Journal of Service Research. 8(2). 131-148.

Hajmásy, Gy. (2018). Társadalmi felelősségvállalás a magyarországi szállodákban: különös tekintettel a környezetvédelemi aspektusra. [In Hungarian, CSR in Hungarian hotels: 
with special regard to the environmental aspect] Turisztikai és Vidékfejlesztési Tanulmányok 3 (3) 4-27, 24.

Karakasné-Morvay, K., \& Daruka, E. (2009). Az elvárások szerepe a szállodai vendégelégedettségben. [In Hungarian, The role of expectations in hotel guest satisfaction.] Turizmus Bulletin, 13 (2) 48-57.

Karakasné-Morvay, K. (2014) Importance and impact of guest satisfaction. Apstract - Applied Studies In Agribusiness And Commerce 8 :4 31-37., 7.

Katawetawaraks, C., \& Wang, C. L. (2011). Online Shopper Behavior: Influences of Online Shopping Decision. Asian Journal of Business Research, 1(2) 66-74.

Kátay, Á. (2015). The causes and behavior-altering effects of hotel guests' dissatisfaction. Journal of Tourism and Services, University College of Business Prague 6 (11) 28-48.

Kolos, K., \& Kövesdi, J. (2020). Az idősek turizmusban való részvétele Magyarországon: motivációk és turisztikai élmények vizsgálata. [In Hungarian, Participation of the elderly in tourism in Hungary: an examination of motivations and tourist experiences] Turizmus Bulletin, 20(1). 25-34

Kotler, P., \& Keller, K. L. (2016). Marketing Management. Pearson Education.

Lóránt, D., Csapó, J., Nagy, Á., \& Töröcsik, M. (2020). Can We Understand Non-Tourism as a Form of Sustainable Tourism? The Role of Lifestyle and Motivations behind NonTraveling Based on the Hungarian Example. Sustainability, 12: 18 Paper: 7353

Lovelock, C. H., Vandermerwe, S., Lewis, B., \& Fernie, S. (2004): Services Marketing. Prentice Hall Europe.

Lőke, Z., Kovács, E., \& Bacsi, Z. (2018). Assessment of Service Quality and Consumer Satisfaction In A Hungarian Spa. Deturope, 10(2), 124-146

Markos-Kujbus, É. (2016). Electronic word-of-mouth as a marketing communications tool. The information role of consumer opinions in the case of TripAdvisor (2016) A CRE8TV Project Deliverable, DEL: 4.3.2(R)., DEL: 4.3.2.(F), 51-69.,

Martin-Fuentes, E., Mellinas, J. P, \& Parra-Lopez, E. (2020). Online travel review rating scales and effects on hotel scoring and competitiveness. Tourism Review. https://doi.org/10.1108/TR-01-2019-0024

Oliver, R. L. (1997). Satisfaction: A Behavioral Perspective on the Consumer. New York: Irwin/McGraw-Hill

Schulze, H., Sidali, K. L., \& Spiller, A. (2009). The Impact of Online Reviews on the Choice of Holiday Accommodations. In: Information and Communication Technologies in Tourism, 87-98

Yen, C-L. A., \& Tang. C-H. H. (2015). Hotel attribute performance, eWOM motivations, and media choice. International Journal of Hospitality Management, 46. 79-88.

Zerényi, K. (2016). Opportunities and limitations of the Likert scale. Opus et Educatio. 3 (4) 470-478. 